\title{
Valuation of Contractual Assets Using Statistical Simulation
}

\author{
Jan Vlachý'
}

ABSTRACT This paper develops a dynamic option-based model for the valuation of rental and other similarly
structured lease contracts under the conditions of uncertainty that is then solved by statistical
simulation (Monte Carlo). The motivation, research background and methodology of the paper
follow up on a previously published general firm-theoretical approach by the author, who takes an
interdisciplinary approach to apply the model in this particular context. It is shown that due to the
path dependency of the problem, Monte Carlo is an appropriate and practical tool for analyzing
embedded options, incident in most rental and lease relationships, and can be used as a major
determinant of their value. In addition to its basic valuation function, exploitable for business ac-
quisition or lease contracting purposes, this Monte Carlo model is very well disposed for various
microeconomic analyses. Accordingly, we demonstrate the particular impacts and sensitivities of
contractual party-specific, as well as environmental, factors including parties' transaction costs, in-
formation asymmetry and enforceability of legal claims.

KEY WORDS: $\quad$ intangibles valuation, rental contracts, embedded options

JEL Classification:

D46, D92, G31, L21

${ }^{1}$ Czech Technical University in Prague - Masaryk Institute of Advanced Studies, Czech Republic

\section{Introduction}

Value-based methods for assessing tangible investments are familiar tools for most decision-makers, constituting a fundamental part of management education and are extensively used for key components of the strategic management process, such as capital budgeting. The essential principles of the discounted cash-flow model have been in the public domain and in regular use by practitioners for at least the last one hundred years (Fischer, 1907; Rubinstein, 2006; Williams, 1938).

\section{-}

Correspondence concerning this article should be addressed to: Jan Vlachý, Czech Technical University in Prague - Masaryk Institute of Advanced Studies, Kolejní 2637/2a, Praha 6, 160 00, Czech Republic. E-mail: jan.vlachy@cvut.cz
More recently, many researchers have expressed that, besides tangible assets, the value of any business may be strongly determined by intangibles (Blair \& Wallman, 2001; Daum, 2001; Lev, 2001; Saaty, 2009) These generally constitute various rights, opportunities and obligations that can substantially enhance and/or diminish the value of a company when compared to the balance of its assets and liabilities, and they may include diverse items, ranging from licenses and brands to specific business skills and market share (Corrado, Hulten, \& Sichel, 2005; Kogut and Zander, 1992; Ortiz, 2006; Wang, Wang, \& Liang, 2014).

Vlachý (2009) embraced the topic within the framework of a comprehensive firm-theoretical model (Table 1) with direct couplings to existing valuation tools based on contemporary financial theory that uses real options. 
Table 1. Value-Based Model of the Firm (Vlachý, 2009)

\begin{tabular}{lll}
\hline 1. Tangible Assets & scarce goods under ownership control \\
\hline 2. Contractual & 2.1 Rights on Tangible Assets & sale, purchase, lease, rent, options... \\
Assets & 2.3 Rights on Opportunities & patents, trademarks, licenses, quotas... \\
\hline 3. Strategy & combination of Tangible and Contractual Assets and their use \\
\hline
\end{tabular}

Vlachý (2010), preceded by Vlachý and Vlachý (2008), has developed this valuation concept for the particular case of contractual assets, i.e., any value, positive or negative, constituted by an outstanding contract, explicit or implicit, between a company and any other party. Such a contract may be concluded either within the firm (e.g., with its employees) or outside of the firm (e.g., with its suppliers, customers, or the state). At the same time, the form of the contract may be either explicit (i.e., formally concluded between counterparties) or implied (i.e., arising from pertaining legislation, standards, custom etc.). Furthermore, Vlachý (2010) has shown that embedded options may substantially impact the contract's value and also determine the precedent negotiating strategy.

This paper focuses on the valuation of contractual assets originated from long-term lease contracts (and, thus, a particular type of rights on tangible assets, as per classification 2.1 in Table 1). Conceptually, it follows up on that by Vlachý and Vlachý (2008), who analyzed contractual situations based on combinations of simple buy-and-sell contracts and their characteristics, analytically deriving closed-form solutions for their valuations. The present problem is much more challenging, however, as it includes an intertemporal structure of path-dependent options, which do not allow generalized closed-form solutions, and the analysis in special cases would typically be too complex to be practicable (Geske, 1979; Wilmott, 2006).

Financial economics describes any right, including the right or opportunity to abandon a commitment, as an option. In contrast to financial options, which are typically conceived as negotiable securities (Hull, 2012), embedded options constitute inseparable components of either financial or real contracts (Davidson \& Levin,
2014; Kling, Russ, \& Schmeiser, 2006; Moore, 2001). These defining attributes notwithstanding, options may materially impact such contracts' values and, in some special cases, this difference (i.e., option value) can be observed empirically (Giaccotto, Goldberg, \& Hedge, 2007; Mitchell, 1991; Myers, 1977).

This paper takes a similar approach, not only focusing on application in commercial rental agreements but also, by analogy, on the assessment of lease situations in general. Its goal is to develop and analyze an option-based model of rental lease valuation and contracting. We shall emphasize their value drivers stemming from termination clauses and transaction costs, which constitute a characteristic feature of contracts in the industry (Goddard \& Marcum, 2012) and, as demonstrated by Fisher and Ciochetti (2007), determine their commercial characteristics. In contrast to Vlachý and Vlachý (2008) and Vlachý (2010), the valuation model uses numerical (Monte Carlo) simulations, which constitutes a considerably more universal approach than closed-form solutions of stochastic differential equations (Breton \& Ben-Ameur, 2005).

The paper is organized as follows: First, the various contractual situations will be described and analyzed within the framework of single-step payoff functions. A dynamic intertemporal valuation model is then developed. Finally, selected simulation results will be discussed, illustrating how the model can bring useful insights into the nature of particular rental-contract value drivers.

\section{Analyzing the Contractual Terms}

We assume two contracting parties, the seller of a service (i.e., lessor), designated $\mathrm{S}$, and its buyer (tenant), designated $\mathrm{B}$. The contract will be stipulated at a mar- 
ket-corresponding fixed price $P$ (rental rate, in monetary unit per sqm).

From the point of view of the seller, the future value of the contract $V_{\mathrm{S}}$ will be contingent on the future market rental rate $p$ as in (1):

$V_{\mathrm{S}}=P-p$

If the buyer has an option to terminate a contract (or, alternatively, its compliance is effectively unenforceable, which will be discussed in more detail in Part 3.3), the seller becomes an issuer of a call option as in (2). This equation clearly constitutes a position with overall negative time value, and the contract would be unacceptable to a rational seller, unless an up-front premium were charged:

$V_{\mathrm{S}}=\min \{P-p ; 0\}$.

In contrast to financial options, it is not customary to charge up-front premiums for embedded options. Other conditions must, therefore, provide for an equilibrium that could lead to negotiable terms. The equilibrium may be conceivably influenced by several factors in real-world tenancy agreements.

Apparently, the seller can simply charge the buyer an above-market rental rate $R>P$ to compensate for the option value. Assuming no additional constraints, such a solution becomes highly unstable, however, because the buyer has an incentive to terminate as soon as possible (i.e., virtually immediately) and renegotiate at the market price $P$.

The buyer must therefore be incentivized to retain tenancy, which can be achieved by stipulating a penalty clause on termination $F$ (an income of the lessor) or with the existence of other transaction costs relating to premises change $C_{\mathrm{B}}$. For these terms to provide a stable solution, it is essential to meet the condition (3):

$F+C_{\mathrm{B}} \geq R-P$.

Such a constraint also allows for solutions at the market price, i.e., $R=P$; however, these are trivial because it suffices to set a prohibitively high $F$, and effectively make the contract irrevocable (provided the penalty is enforceable).
The value of the contract with an embedded termination right may, thus, ensue solely from a termination penalty $F$, or from its combination with an adjusted rental rate $R>P$, both of which are summarily described by (4). This is similar to a short position in an instrument that financial market practitioners usually call a cancellable forward or Boston option (Kat, 1994; Rawls \& Smithson, 1989)

$V_{\mathrm{S}}=\min \{R-p ; F\}$, assuming $R \geq P$ and $F \geq R-P$.

In either case, the buyer's and seller's positions are symmetric, i.e., $V_{\mathrm{B}}=-V_{\mathrm{S}}$. This simple equilibrium characteristic, where both parties are expected to settle at an initial expected value of the contract equal to zero (for a comprehensive review of various approaches leading to this assumption, see Chow, McAleer and Sequeira (2000)) ceases to hold once transaction and opportunity costs of termination (e.g., moving, cleanup, refurbishment, commissions, vacancy) are taken into account.

For generalization, we shall allow for transaction costs borne by the buyer $C_{\mathrm{B}}$, as well as by the seller $C_{\mathrm{S}}$. This results in contract value according to (5) from the point of view of the seller, (6) from the point of view of the buyer, both of which are illustrated in Figure 1.

$V_{\mathrm{S}}=\min \left\{R-p ; F+C_{\mathrm{B}}\right\}-D$, where $D=C_{\mathrm{B}}+C_{\mathrm{S}}$ for $p<\left(R-F-C_{\mathrm{B}}\right)$, else $D=0$, assuming $R \geq P$ and $F+C_{\mathrm{B}} \geq R-P$;

$V_{\mathrm{B}}=\max \left\{p-R ;-F-C_{\mathrm{B}}\right\}$

The technical term $D$ contained in the sum (5) represents a cash-or-nothing binary (digital) call option (Rubinstein \& Reiner, 1991).

Wherever $V_{\mathrm{B}} \neq-V_{\mathrm{S}}$, as in (5) as opposed to (6), the two different values do not constitute an equilibrium. In case of $V_{\mathrm{S}}<-V_{\mathrm{B}}$, whenever $C_{\mathrm{B}}+C_{\mathrm{S}}>0$, the negotiation turns into a negative-sum game. This is a crucial finding because using conventional game-theoretical criteria (Vega-Redondo, 2003) and assuming transactional costs of moving are positive, rational contractors would be expected to generally avoid agreements including termination options.

That such agreements are being negotiated in practice and that they actually constitute the majority of 

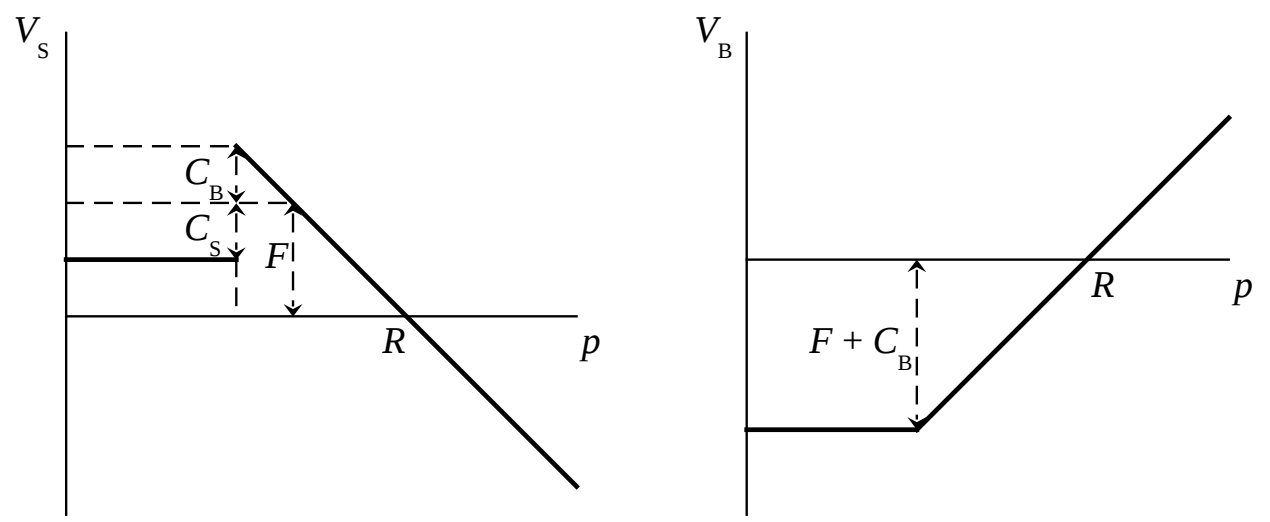

Figure 1. Seller's and Buyer's Payoff Functions.

long-term rental contracts, can only be explained by the fact that various market inefficiencies let sellers generate sufficient margins to sustain business in a primarily demand-driven market (this market feature is investigated in detail by Kholdy and Sohrabian (2008) and Baum (2009)). In other words, lessors will end rental contracts that, on a stand-alone basis, have negative value while still retaining positive value on their development projects.

Actual pricing will thus be based primarily on the assessment of $V_{\mathrm{B}}$, rather than $V_{\mathrm{S}}$, whereby $C_{\mathrm{S}}$ becomes irrelevant. However, this pricing structure would have an impact if the preponderance of sellers with high transaction costs were to to push down the benchmark rates $P$ for contracts without termination options; this would be characteristic in a market with very high vacancy rates, as shown by Sivitanides (1997).

\section{Developing a Multi-Period Valuation Model}

A regular rental contract is usually long term, with potential termination risk arising during its duration, contingent on the temporal development of the market rental rate as well as on the contractual covenants.
Any realistic model has to take an intertemporal view, which results in valuation situations composed of compound options.

Despite the existence of analytical solutions for particular types of compound options (Geske, 1979), it is much more efficient and universal to adopt a numerical approach. Discrete numerical analysis methods for the valuation of options can be divided into two fundamental categories. One is based on the simple and elegant backward-induction lattice model introduced by Cox, Ross and Rubinstein (1979), Rendleman and Barter (1979), and Sharpe (1978), which in absolute usage terms, is currently the preferred method for evaluating miscellaneous types of options, including real and embedded (Mun, 2012; Reuter \& Tong, 2007).

The alternative, which is used in this study, exploits statistical simulation (Monte Carlo). This technique, initially developed during World War II (Metropolis \& Ulam, 1949), and long common for miscellaneous applications in areas ranging from Neurology to Technology to Natural Sciences (Fishman, 1996), was initially proposed for option valuation by Boyle (1977). It has not gained much acceptance for the val- 
Table 2. Contractual Terms as a Function of Rental Rate Volatility.

\begin{tabular}{lllllll}
\hline $\boldsymbol{\sigma}$ & $\mathbf{5 \%}$ & $\mathbf{1 0 \%}$ & $\mathbf{2 0 \%}$ & $\mathbf{3 0 \%}$ & $\mathbf{4 0 \%}$ & $\mathbf{5 0 \%}$ \\
\hline$\varphi=\pi(\mathrm{t}=10)$ & $4 \%$ & $8 \%$ & $17 \%$ & $25 \%$ & $33 \%$ & $42 \%$ \\
$\varphi=\pi(\mathrm{t}=20)$ & $6 \%$ & $12 \%$ & $25 \%$ & $37 \%$ & $49 \%$ & $61 \%$ \\
$\varphi=\pi(\mathrm{t}=30)$ & $7 \%$ & $15 \%$ & $30 \%$ & $44 \%$ & $58 \%$ & $72 \%$ \\
\hline
\end{tabular}

Table 3. Price Premium as a Function of Rental Rate Volatility Assuming Fixed Penalty.

\begin{tabular}{lcccccc}
\hline $\boldsymbol{\varphi}$ & $\mathbf{2 0 \%}$ & \multicolumn{3}{c}{$\mathbf{3 0 \%}$} \\
\hline$\sigma$ & $10 \%$ & $20 \%$ & $30 \%$ & $20 \%$ & $30 \%$ & $40 \%$ \\
$\pi(\mathrm{t}=10)$ & $4 \%$ & $15 \%$ & $27 \%$ & $11 \%$ & $23 \%$ & $36 \%$ \\
$\pi(t=20)$ & $9 \%$ & $27 \%$ & $48 \%$ & $21 \%$ & $42 \%$ & $66 \%$ \\
$\pi(t=30)$ & $12 \%$ & $35 \%$ & $64 \%$ & $29 \%$ & $57 \%$ & $88 \%$ \\
\hline
\end{tabular}

uation of most financial options, with the exception of certain types of path-dependent exotic options (Wilmott, 2006), primarily because of its relatively high computing-power demands, it has a strong potential for solving particular real-option problems and path-dependent embedded options (Charnes, 2012; Mun, 2006; Onimus, 2011).

The present simulation model is designed as follows: A contract is negotiated for $n$ periods (years) at the price (rental rate) $R$, with the buyer holding an option to terminate at any discrete time step of the simulation $\Delta t$. If and when the option is exercised, the buyer pays the seller the amount $F$, bears an additional cost $C_{\mathrm{B}}$, and the seller bears a cost $C_{\mathrm{S}}$; a new rental agreement is then contracted at the price $r_{t}$, derived from the current market price $p_{\mathrm{t}}$ and original premium $\pi$, stated as a percentage of the rental price commensurate with (9). Exercise (termination) by the tenant is contingent on the criterion (7), in accordance with (6):

$p_{\mathrm{t}}<R-F-C_{\mathrm{B}}$.

The market price $p_{\mathrm{t}}$ is generated as an opportune stochastic process. The simulations in Part 3 will assume its log-normal Brownian diffusion described by (8), where $\mu$ represents the price's expected periodical trend, $\sigma$ its standard deviation (volatility), and $\varepsilon$ a random value with normalized normal distribution.

$p_{\mathrm{t}+\Delta \mathrm{t}}=p_{t} \exp \left[\left(\mu-\sigma^{2} / 2\right) \Delta t+\sigma \varepsilon \sqrt{\Delta t}\right]$.

To generalize the results, the rental premium $\pi$, termination penalty $\phi$ and transaction $\operatorname{costs} \chi_{\mathrm{B}}, \chi_{\mathrm{S}}$ are each standardized as percentage values of the rental price $R$, using the parameters as in (9), (10), (11) and (12).

$\pi=R / P-1$

$\phi=F / R$

$\chi_{\mathrm{B}}=C_{\mathrm{B}} / R$

$\chi_{\mathrm{s}}=C_{\mathrm{s}} / R$.

Thus, the actual rate $R$ becomes irrelevant (i.e., can be perceived as unit). Furthermore, the initial contracting constraint (3) may be restated as (13):

$\phi+\chi_{\mathrm{B}} \geq \pi /(\pi+1)$. 
Table 4. Contractual Terms $(\varphi=\pi)$ as Functions of Buyer's Transaction Costs $(\sigma=25 \%)$.

\begin{tabular}{llllllll}
\hline $\mathbf{X}$ & $\mathbf{0}$ & $\mathbf{1 0 \%}$ & $\mathbf{2 0 \%}$ & $\mathbf{3 0 \%}$ & $\mathbf{4 0 \%}$ & $\mathbf{5 0 \%}$ & $\mathbf{6 0 \%}$ \\
\hline$\varphi=\pi(\mathrm{t}=10)$ & $20 \%$ & $17 \%$ & $14 \%$ & $11 \%$ & $8 \%$ & $5 \%$ & $3 \%$ \\
$\varphi=\pi(\mathrm{t}=20)$ & $30 \%$ & $27 \%$ & $23 \%$ & $19 \%$ & $16 \%$ & $12 \%$ & $9 \%$ \\
$\varphi=\pi(\mathrm{t}=30)$ & $37 \%$ & $33 \%$ & $29 \%$ & $25 \%$ & $21 \%$ & $17 \%$ & $13 \%$ \\
\hline
\end{tabular}

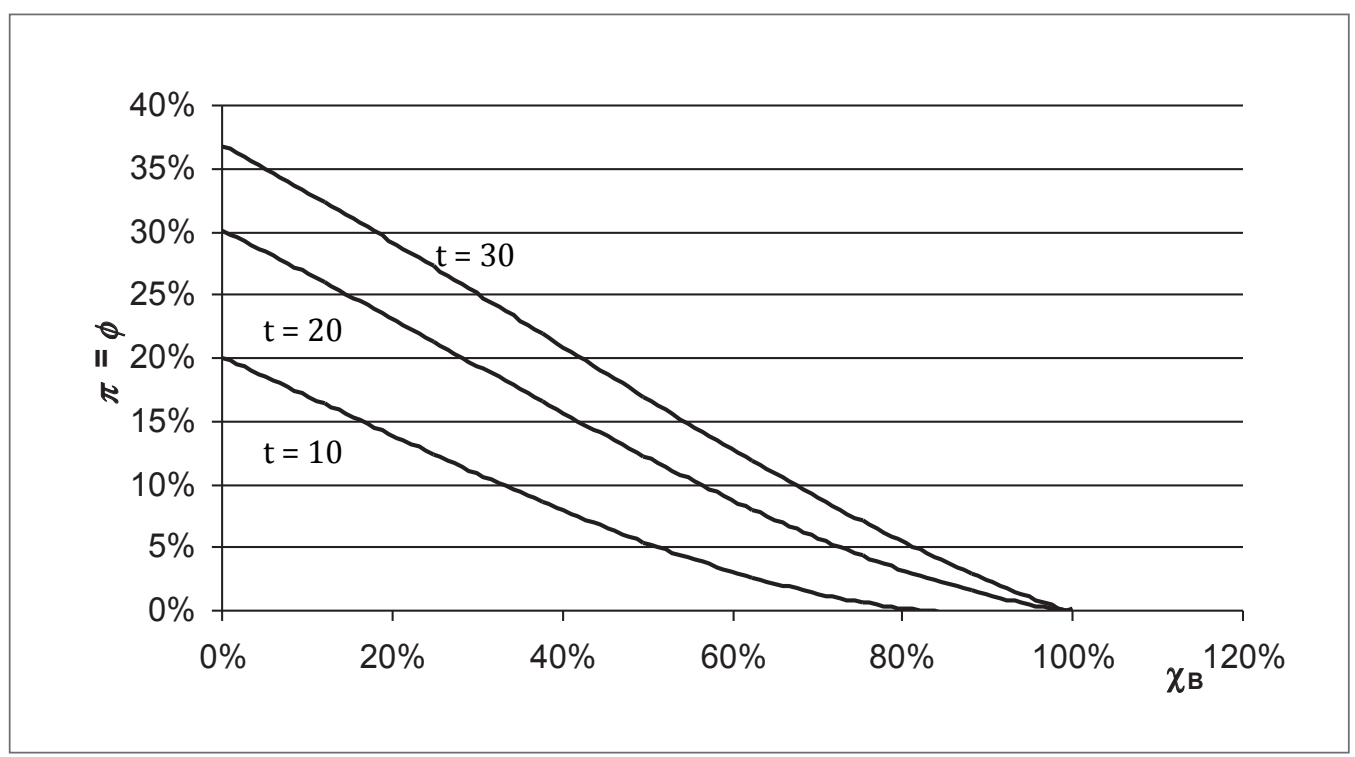

Figure 2. Contractual Terms $(\varphi=\pi)$ as Functions of Buyer's Transaction Costs ( $\sigma=25 \%)$.

\section{Discussion of Assorted Model Solutions}

The model can be utilized for diverse value-based analyses. Moreover, for example, facilitating actual contracting or providing valuation data for M\&A transactions, it may also serve to quantify the various sensitivities arising from relevant contractual and market terms. An illustration of this approach will be given herein, complementing the essential findings in Part 2 and offering a better insight into some of the key value drivers for rental agreements.

In each case, the mean discounted value of the simulation ${ }^{\star} V$ is benchmarked against the $N P V$
(Net Present Value) of rental incomes, contracted for a lease with the equivalent time horizon $n \Delta t$ at the current market price $p_{0}=P$ with no termination rights $\left(V_{\mathrm{BENCH}}\right)$. Equilibrium of particular contracted terms is then derived by numerically iterating ${ }^{*} V \rightarrow V_{\mathrm{BENCH}}$.

Results have been calculated for contractual maturities of $n=\{10 ; 20 ; 30\}$ (years) and the discount rate $r=5 \%$, with no price trend anticipated $(\mu=0)$. All simulations have been performed using Crystal Ball simulation software (for details on its characteristics see, e.g., Charnes, 2012; Harris, 2014), set at 10,000 experimental runs. 


\subsection{Price Premium and Termination Penalty as Functions of Price Volatility}

The first set of simulations omits transaction costs and seeks various cases of contracting equilibrium. One apparently reasonable strategy is setting the termination penalty equal to the price premium, which incidentally meets criterion (13). This means deriving the function $\phi=\pi=f(\sigma)$ while leaving the other parameters unchanged at $\chi_{\mathrm{B}}=0, \chi_{\mathrm{S}}=0$.

The results in Table 2 suggest that, interestingly, there is a linear relationship between $\phi=\pi$ and $\sigma$, whose slope is solely determined by the contract's duration and converging toward perpetuity. This seems to suggest a useful contracting heuristic. Unfortunately, situations with high price volatility and/or long contract durations then result in very high levels of termination penalties (higher, for example, than $50 \%$ of the annual rent), which may not be commercially viable, and might even be legally or practically unenforceable, as discussed in more detail in Part 3.3.

Alternatively, it is possible to set a fixed termination penalty and investigate the related equilibrium price premium. This mitigates the risk of the penalty not being enforceable, however, as shown in Table 3, it may lead to unstable solutions (highlighted in italics) due to the tenant's immediate incentive to terminate, as they do not meet the criterion $\phi>\pi /(\pi+1)$, i.e., the applicable special case of (13).

\subsection{Impact of Transaction Costs}

Formulas (4) and (5) indicate that the seller's transaction costs do not impact termination; they only reduce the seller's payoff on termination. On the other hand, the buyer's transaction costs diminish his inclination to terminate, but, in contrast to the termination penalty, do not increase the seller's payoff on termination. In a buyer's market, it is only the tenant's transaction costs and the termination penalty that influence the terms of the contract.

These will now be examined using a reasonable volatility assumption (Kanak \& Tien, 2000) of $\sigma=25 \%$ and, again, setting $\phi=\pi$. We derive the function $\phi=\pi=f\left(\chi_{\mathrm{B}}\right)$.

The results in Table 4 and Figure 2 show that increasing transaction costs $\chi_{\mathrm{B}}$ borne by the tenant markedly decrease the premium and termination penalty levels that the lessor will be able to charge for the option to terminate, i.e., offer a more competitive contract (intuitively, all results converge toward zero when it becomes prohibitive for the tenant to terminate).
One of the interesting conclusions of this simulation that can be further investigated in game-theoretical settings, relates to the fact that the lessor may be in a position to discriminate between different tenants based on the recognition of their disparate transaction costs. On the other hand, tenants can improve their negotiating position by inflating lessors' expectations in this respect.

\subsection{Impact of Imperfect Enforcement}

As detailed by Farnsworth (1970), Mattei (1995), Miller (2004) and García (2012), different jurisdictions take diverse approaches in respect to penalty clauses and each may result in particular constraints as concerns their actual enforceability.

Summarily, common law tends to render penalty clauses unenforceable in deference to the just compensation principle, which essentially means that the clause may not serve to coerce the defaulting promisor into avoiding contractual breach, but a liquidated damages clause is deemed acceptable, provided it is deemed to represent a genuine pre-estimate of damages. On the other hand, civil law generally permits sanctions, but judges may be allowed or required to moderate contract penalties which are deemed grossly excessive. In addition to such specifics, the net costs of enforcement (including opportunity costs) may make some claims dormant, not to mention judicial environments that simply do not guarantee credible recovery (Aboal, Noya, \& Rius, 2014).

With regard to the present model, any effect made by these factors bears on the expected values of $\phi, \chi_{S}$ and $\chi_{B}$, respectively (even though $\chi_{\mathrm{s}}$ does not directly impact contracting decisions, it affects the value of the lessor's assets). Furthermore, parties' expectations may differ in this respect, for example, when one is domestic (and, thus, presumably more realistic) and the other one is foreign.

The model clearly shows that a decrease in expected termination penalty recovery will result in either higher lease premiums (i.e., increased effective rental rates), or, in case they would exceed criterion (13), a reluctance to conclude long-term contracts.

\section{Conclusions}

In this paper, we have developed and applied a dynamic model for the valuation of rental and similar contracts that is based on appropriate payoff functions. Statistical simulation has been shown to be a flex- 
ible time- and cost-efficient method for solving the model. In addition to its straightforward application for quantitative support in contracting or M\&A situations, a microeconomic approach has been suggested because it facilitates a proper understanding of market dynamics and value-driver sensitivities.

We have thus shown how termination rights become less valuable as a result of tenants' transaction costs on the one hand and more valuable with increasing market volatility on the other hand. Lessors' transaction costs are irrelevant from the contracting point of view, but they are important in terms of assessing the value of the contract for that party. In addition to other factors, actual negotiation results will be affected by the lessor's capability to correctly estimate the tenant's transaction costs. The lessor may also be able to effectively discriminate between tenants due to information asymmetry characteristics.

The findings of this paper are both methodological as well as theoretical. On the one hand, empirical-data calibration and parametrical adjustments can turn the model into a management tool suitable for valuation or negotiation support. On the other hand, further research opportunities include, for example, using outputs of the model for a game-theoretic analysis of rental contract negotiation as well as for implicit parametrization in macroeconomic studies.

\section{References:}

Aboal, D., Noya, N., \& Rius, A. (2014). Contract enforcement and investment: A systematic review of the evidence. World Development, 64, 322-338.

Baum, A. (2009). Commercial Real Estate Investment. New York, NY: Taylor \& Francis.

Boyle, P. P. (1977). Options: A Monte Carlo approach. Journal of Financial Economics, 4(3), 323-338.

Blair, M. M., \& Wallman, S. M. H. (2001). Unseen wealth: Report of the brookings task force on intangibles. Washington DC: Brookings Institution Press.

Breton, M., \& Ben-Ameur, H. (2005). Numerical methods in finance, New York, NY: Springer.

Charnes, J.M. (2012). Financial modeling with oracle crystal ball and excel. ( $2^{\text {nd }}$ ed.). Hoboken, NJ: John Wiley \& Sons.

Chow, Y. F., McAleer, M., \& Sequeira, J. M. (2000). Pricing of forward and futures contracts. Journal of Economic Surveys, 14(2), 215-253.
Corrado, C., Hulten, C., \& Sichel, D. (2005). Measuring capital and technology: An expanded framework. In C. Corrado, J. Haltiwanger \& D. Sichel (Eds.), Measuring capital in the new economy. National Bureau of Economic Research, Studies in income and wealth (Vol.65, pp. 11-45). Chicago, IL: University of Chicago Press.

Cox, J. C., Ross, S. A., \& Rubinstein, M. (1979). Option pricing: A simplified approach. Journal of Financial Economics, 7(3), 229-263.

Daum, J. (2001, July 26). How accounting gets more radical in measuring what really matters to investors. The New Economy Analyst Report. Available from http://juergendaum.com/ news/07_26_2001.htm

Davidson, A., \& Levin, A. (2014). Mortgage valuation models: embedded options, risk and uncertainty. Oxford, UK: Oxford University Press.

Farnsworth, E. A. (1970). Legal remedies for breach of contract. Columbia Law Review, 70(7), 1145-1216.

Fischer, I. (1907). The rate of interest: Its nature, determination and relation to economic phenomena. New York, NY: Macmillan.

Fisher, L. M., \& Ciochetti, B. A. (2007). Determinants of the terms and performance of office leases. (Working Paper No. 133). Real Estate Research Institute. Retrieved from http://www.reri.org/research/article_pdf/wp133.pdf

Fishman, G. S. (1996). Monte Carlo: concepts, algorithms, and applications. New York, NY: Springer.

García, I. M. (2012). Enforcement of penalty clauses in civil and common law: A puzzle to be solved by the contracting parties. European Journal of Legal Studies, 5(1), 98-123.

Geske, R. (1979). The valuation of compound options. Journal of Financial Economics, 7(1), 63-81.

Giaccotto, C., Goldberg, G. M., \& Hedge, S. P. (2007). The value of embedded real options: Evidence from consumer automobile lease contracts. Journal of Finance, 42(1), 411-445.

Goddard, G. J., \& Marcum, B. (2012). Real estate investment. Berlin: Springer.

Harris, M. (2014). Inside the Crystal Ball: How to make and use forecasts. Hoboken, NJ: John Wiley.

Hull, J. C. (2012). Options, futures and other derivatives ( $8^{\text {th }}$ ed.). New Jersey, NJ: Prentice Hall. 
Kanak, P., \& Tien, F. S. (2000). Implied volatility in the U.K. Commercial property market: Empirical evidence based on transaction data. The Journal of Real Estate Finance and Economics, 20(1), 5-24.

Kat, H. M. (1994). Contingent premium options. Journal of Derivatives, 1(4), 44-55.

Kholdy, S., \& Sohrabian, A. (2008). Capital gain expectations and efficiency in the real estate markets. Journal of Business \& Economics Research, 6(4), 43-52.

Kling, A., Russ, J., \& Schmeiser, H. (2006). Analysis of embedded options in individual pension schemes in Germany. The Geneva Risk and Insurance Review, 31(1), 43-60.

Kogut, B., \& Zander, U. (1992). Knowledge of the firm, combinative capabilities and the replication of technology. Organization Science, 3(3), 383-397.

Lev, B. (2001). Intangibles: Management, measurement, and reporting. Washington, DC: Brookings Institution Press.

Mattei, U. (1995). The comparative law and economics of penalty clauses in contracts. American Journal of Comparative Law, 43(3), 427-444.

Metropolis, N., \& Ulam, S. (1949). The Monte Carlo method. Journal of the American Statistical Association, 44(247), 335-341.

Miller, L. (2004). Penalty clauses in England and France: A comparative study. International and Comparative Law Quarterly, 53(1), 79-106.

Mitchell, K. (1991). The call, sinking fund, and term to maturity features of corporate bonds: An empirical investigation. Journal of Financial and Quantitative Analysis, 26(2), 201-222.

Moore, W. T. (2001). Real options and option-embedded securities. New York, NY: John Wiley \& Sons.

Mun, J. (2006). Modeling risk: Applying Monte Carlo simulation, real options analysis, forecasting and optimization techniques. Hoboken, NJ: John Wiley \& Sons.

Mun, J. (2012). Real options analysis: Tools and techniques for valuing strategic investments and decisions. Hoboken, NJ: John Wiley \& Sons.

Myers, S. C. (1977). Determinants of corporate borrowing. Journal of Financial Economics, 5(2), 147-175.

Onimus, J. C. (2011). Assessing the economic value of venture capital contracts: An option pricing approach. Wiesbaden: Springer Science.
Ortiz, M. A. A. (2006). Intellectual capital (intangible assets) valuation considering the context. Journal of Business \& Economics Research, 4(9), 35-42.

Rawls, S. W., \& Smithson, C. W. (1989). The evolution of risk management products. Journal of Applied Corporate Finance, 1(4), 18-26.

Rubinstein, M., \& Reiner, E. (1991). Unscrambling the binary code. Risk, 4(9), 75-83.

Rendleman, R. J., \& Barter, B. J. (1979): Two state option pricing, Journal of Finance, 34(5), 1092-1110.

Reuer, J. J., Tong, T. W. (2007). How Do Real Options Matter? Empirical Research on Strategic Investments and Firm Performance. In J. J. Reuer, T. W. Tong (ed.), Real Options Theory (Advances in Strategic Management, Vol. 24, pp. 145-173). Oxford, UK: JAI Press.

Rubinstein, M. (2006). A history of the theory of investments. Hoboken, NJ: John Wiley \& Sons.

Saaty, T. L., Sagir, M. (2009). Extending the measurement of tangibles to intangibles. International Journal of Information Technology \& Decision Making, 8(1), 7-27.

Sharpe, W. F. (1978). Investments. Englewood Cliffs, NY: Prentice-Hall.

Sivitanides, P. S. (1997). The rent adjustment process and the structural vacancy rate in the commercial real estate market. Journal of Real Estate Research, 13(2), 195-210.

Vega-Redondo, F. (2003). Economics and the theory of games. Cambridge, UK: Cambridge University Press.

Vlachý, J. (2009). Strategie podniku a finanční teorie [Corporate Strategy and Financial Theory]. Politická ekonomie, 57(2), 147-162.

Vlachý, J. (2010). Assessing and negotiating commercial contracts. The Romanian Economic Journal, 13(37), 143-163.

Vlachý, J. (2008). The effect of cancellation rights on the value of contracts. European Financial and Accounting Journal, 3(2), 51-69.

Wang, Z., Wang, N., \& Liang, H. (2014). Knowledge sharing, intellectual capital and firm performance. Management Decision, 52(2), 230-258.

Williams, J. B. (1938). Theory of investment value. Cambridge, MA: Harvard University Press.

Wilmott, P. (2006). Paul Wilmott on Quantitative Finance ( $2^{\text {nd }}$ ed.). Hoboken, NJ: John Wiley and Sons. 
